\title{
Comparison of fast neutron spectra in graphite and FLINA salt inserted in well-defined core assembled in LR-0 Reactor
}

\author{
Michal Košt’ál* ${ }^{1}$; Martin Veškrna ${ }^{2}$, František Cvachovec ${ }^{3}$, Bohumil Jánský ${ }^{1}$, Evžen Novák ${ }^{1}$, \\ Vojtěch Rypar ${ }^{1}$, Ján Milčák ${ }^{1}$, Evžen Losa ${ }^{1}$, Filip Mravec ${ }^{2}$, Zdeněk Matěj je Jiří Rejchrt ${ }^{1}$, \\ Benoit Forget ${ }^{4}$, Sterling Harper ${ }^{4}$ \\ ${ }^{1}$ Research Center Rez Ltd, 25068 Husinec-Rez 130, Czech Republic \\ ${ }^{2}$ Masaryk University, Botanická 15, Brno 612 00, Czech Republic \\ ${ }^{3}$ University of Defence, Kounicova 65, Brno 612 00, Czech Republic \\ ${ }^{4}$ Massachusetts Institute of Technology, Department of Nuclear Science and Engineering, 77 \\ Massachusetts Avenue, Building 24, Cambridge, MA 02139, United States \\ Email: Michal.Kostal@cvrez.cz \\ Telephone: +420266172655
}

\begin{abstract}
The present paper aims to compare the calculated and measured spectra after insertion of candidate materials for the Molten salt reactor / Fluoride cooled high temperature reactor reactor system concept into the LR-0 reactor. The calculation is realized with MCNP6 code using ENDF/B-VII.0, JEFF-3.1, JENDL-3.3, JENDL-4, ROSFOND-2010 and CENDL-3.1 nuclear data libraries. Additionally, comparisons between the slowing down power of each media were performed. The slowing down properties are important parameters affecting the thickness of moderator media in a reactor.
\end{abstract}

\section{Introduction}

Graphite and fluorine salts like LiF-NaF or $\mathrm{LiF}_{-} \mathrm{BeF}_{2}$ salts (hereinafter FLINA and FLIBE respectively) with highly enriched ${ }^{7} \mathrm{Li}$ isotope are strong candidates for generation IV reactor designs such as the HTGR (High temperature Graphite Reactor) and FHR (Fluoride cooled High temperature Reactor) or MSR (Molten Salt Reactor). Consequently, there is strong interest in experiments which study reactors composed of graphite and fluoride salts which are important for correct calculation of slowing down properties and also for description of neutron spectra on the structural components of FHR/MSR systems.

The intent of this paper is to present neutron spectra measurements in various configurations in the center of the driver core and compare these measurements to Monte Carlo simulations using various nuclear data libraries. The configurations tested include FLINA salt, graphite insertions and a void center channel. In this paper, FLINA salt with natural Li enrichment was used due to limited availability of high enriched ${ }^{7} \mathrm{Li}$ salt. The fluorine content in FLINA is comparable to that of FLIBE, the primary candidate for FHR systems, thus any discrepancies in ${ }^{19} \mathrm{~F}$, as observed by Kato et al 2014 , should be observed in either salt. The experiments were performed in the LR-0 reactor which is a light water reactor that achieves criticality by increasing moderator level. These experiments are performed in the frame of The Memorandum of Understanding on nuclear power between the Czech Ministry of Trade and Industry and the U.S. DOE (DOE 2013). 


\section{Reactor arrangement}

The measurements were performed in a special core assembled in the experimental zeropower reactor LR-0 (Research Centre Řež ltd.). Reactor LR-0 located in Rež near Prague (Czech Republic) is an experimental, light-water-moderated zero-power reactor originally designed for research of VVER-1000 and VVER-440 type reactor cores, spent-fuel storage lattices, and for benchmark experiments.

Power control in this core arrangement is achieved by changing the moderator level. Power control can also be realized by adjusting insertion of control rods in certain core configurations. The LR-0 fuel elements are radially identical, but axially shorter than a VVER-1000 fuel assembly. Continuous maximal operating power is $1 \mathrm{~kW}$ with thermal neutron flux density $\approx 10^{9} \mathrm{n} \mathrm{cm}^{-2} \mathrm{~s}^{-1}$.

The main feature of the LR-0 is the flexibility of the supporting structures allowing arbitrary composition of core. In the experiment six fuel assemblies surrounds the experimental dry assembly where the studied media (graphite, void or FLINA) is inserted. The spacing grids and also experimental dry assembly have hexagon key dimension $23.4 \mathrm{~cm}$, the lattice pitch is $23.6 \mathrm{~cm}$. It means between adjoining assemblies there are $2 \mathrm{~mm}$ gap. Around the core there are aluminum dry channels with inner diameters of $7 \mathrm{~cm}$ and thickness of $5 \mathrm{~mm}$ that contain detectors. The detail layout of the core can be found in Figure 1, with the detailed center channel configurations in Figure 2. Slight enrichment variations of the as-fabricated assemblies are observed and were modeled using precise uranium inventory data. .

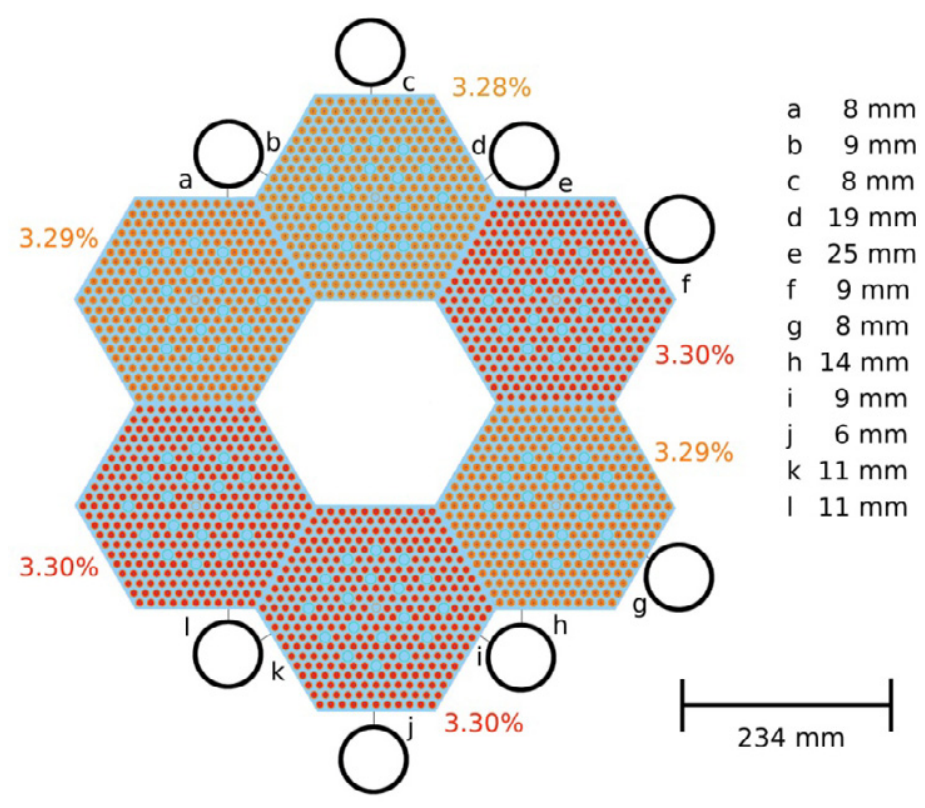

Figure 1.: Radial cross-section of the core with specified enrichment, the distances are upright from pin 


\section{Experimental and calculation methods}

\subsection{Measuring arrangement}

Neutron spectra in the 0.8 to $10 \mathrm{MeV}$ energy range were measured via the proton-recoil method using a Stilbene scintillator $(10 \times 10 \mathrm{~mm})$ with neutron and gamma pulse shape discrimination (hereinafter Stilbene).

The two-parameter spectrometric system (Veskrna et al 2014) is fully digitized and it is able to process up to 100000 impulses per second in energy range from 0.8 to $15 \mathrm{MeV}$. The input analog signal from photomultiplier is divided in the amplifier into two branches. Each branch is differently amplified and digitized by separate analog to digital converters. This different amplification increases the dynamic range of particle energies so that the spectrometer is capable of processing and increase the signal to noise ratio. Two fast analog to digital converters working on sampling frequency $1 \mathrm{GHz}$ are used and the digital signal processing is implemented in field-programmable gate array. Therefore it is able to process all data flow from both analog to digital converters without any dead time. Pulse shape discrimination is realized by integration method which principle lies in comparison of area limited by a trailing edge of the measured response with area limited by the whole response. Deconvolution of recoiled proton spectra was performed using Maximum Likelihood Estimation (Cvachovec J. et al., 2008).

Neutron spectra below 1.3 MeV were measured using a hydrogen chamber (hereinafter HPC), operated at $400 \mathrm{kPa}$ in the 0.111 to $0.368 \mathrm{MeV}$ energy range and at $1000 \mathrm{kPa}$ in the higher range (Jansky et al 2014).

\subsection{Experimental arrangement}

The tested material geometry (Figure 2) composes of 6 blocks. Both graphite (Case B) and salt blocks (Case C) have the same dimensions. Graphite blocks are uncladded, as they are milled from bigger blocks, while the FLINA salt is contained in aluminum canisters with 5 $\mathrm{mm}$ wall thickness. The length of both salt cask and graphite block is $60 \mathrm{~cm}$. Thus the salt length is $59 \mathrm{~cm}$ because of Al container. The void hexagonal tube (Case A) is also studied. In this case the special experimental dry assembly is filled by air. The axial plot is in Figure 3. .
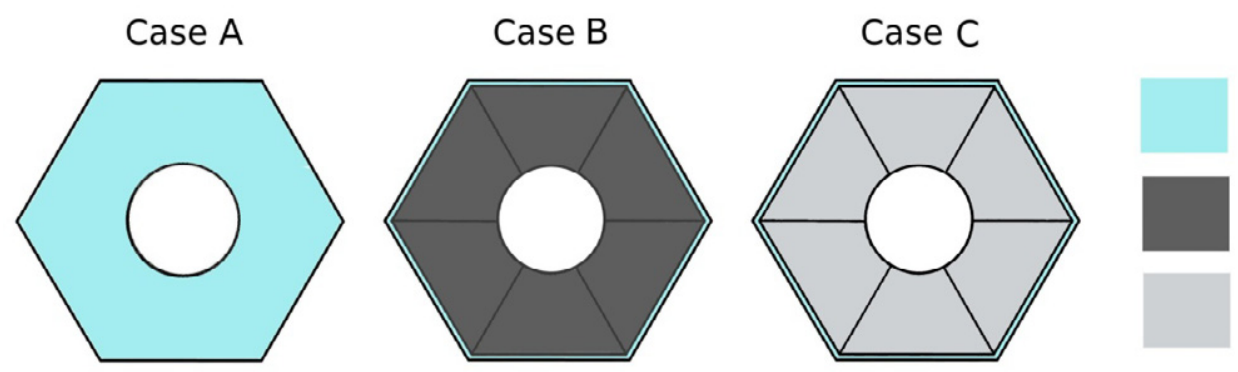

Void

Graphite

FLINA

Figure 2.: Various configurations of core insertion 


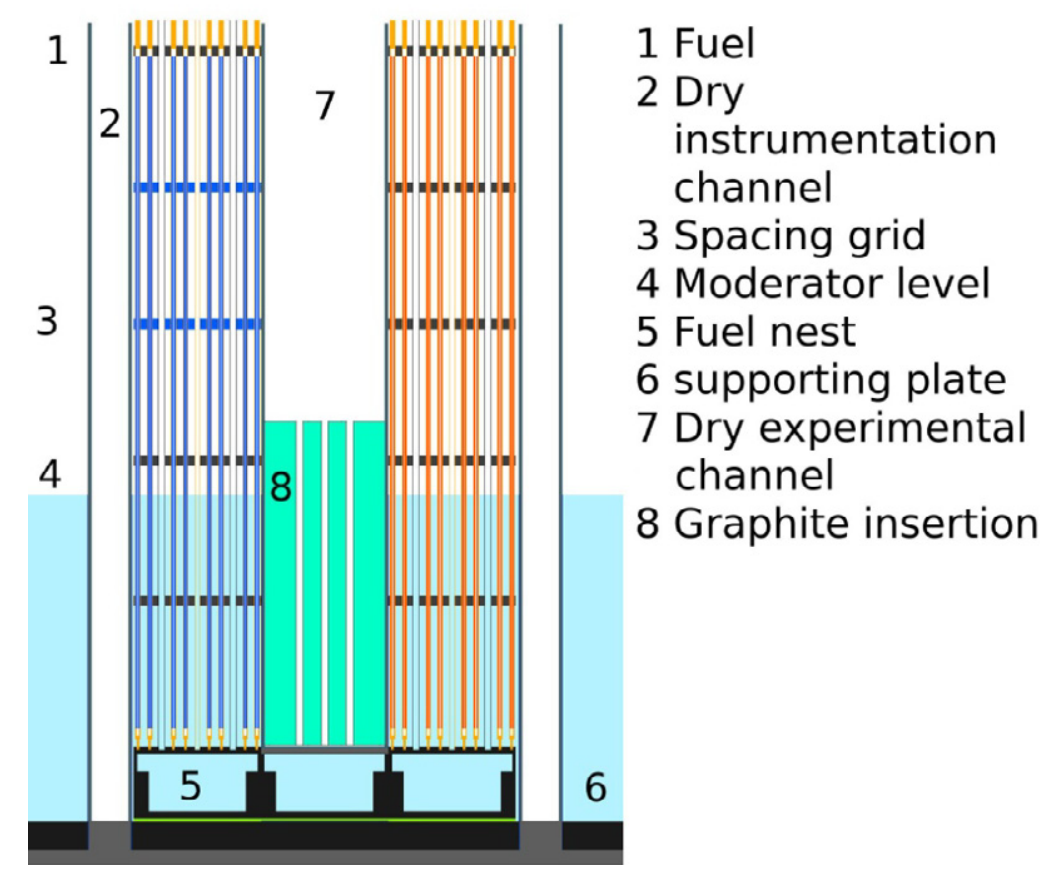

Figure 3.: Axial section of core with graphite insertion (Kostal et al 2014)

The graphite used in this experiment has a density of $1.72 \mathrm{~g} / \mathrm{cm}^{3}$ and impurities concentration below $0.2 \mathrm{ppm}$ of boron equivalent. The FLINA salt, one of the possible materials planned for the reactor system, has a composition of $60 \% \mathrm{LiF}+40 \% \mathrm{NaF}$ and density of, $1.72 \mathrm{~g} / \mathrm{cm}^{3}$.

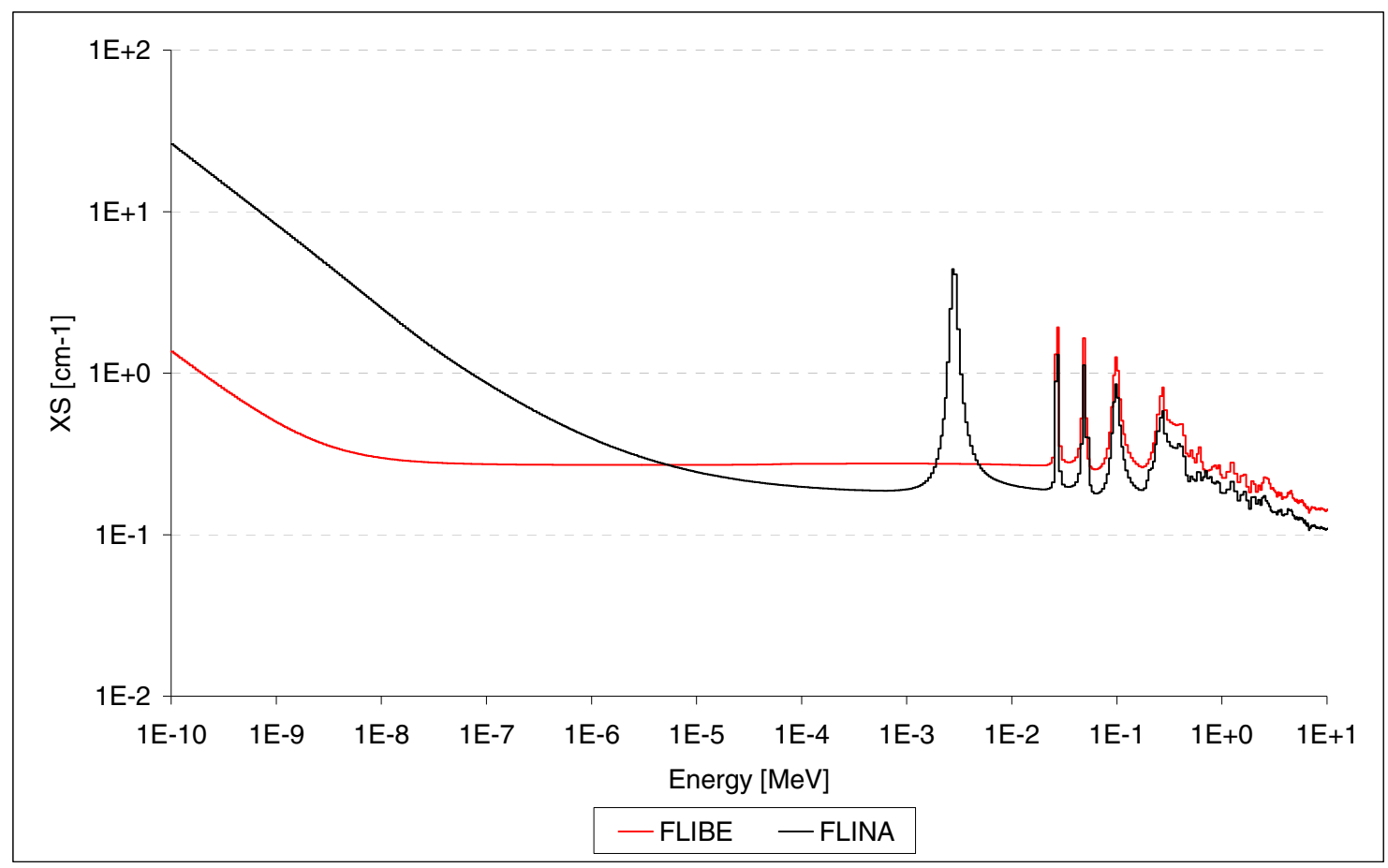

Figure 4.: Comparison of FLIBE and FLINA macroscopic cross section 
In this experiment only the fast neutron flux distribution was studied. This slowing down between 0.1 and $10 \mathrm{MeV}$ can be understood as first part of thermalization. The thermal fluxes were not measured due to occurrence of ${ }^{6} \mathrm{Li}$ in the FLINA which significantly changes the thermal neutron distribution (Figure 5). The thermal neutron distribution will be measured in ${ }^{7} \mathrm{Li}$ enriched FLIBE in frame of common measurement with ORNL (DOE 2013). These FLINA experiments are preliminary ones to those with FLIBE.

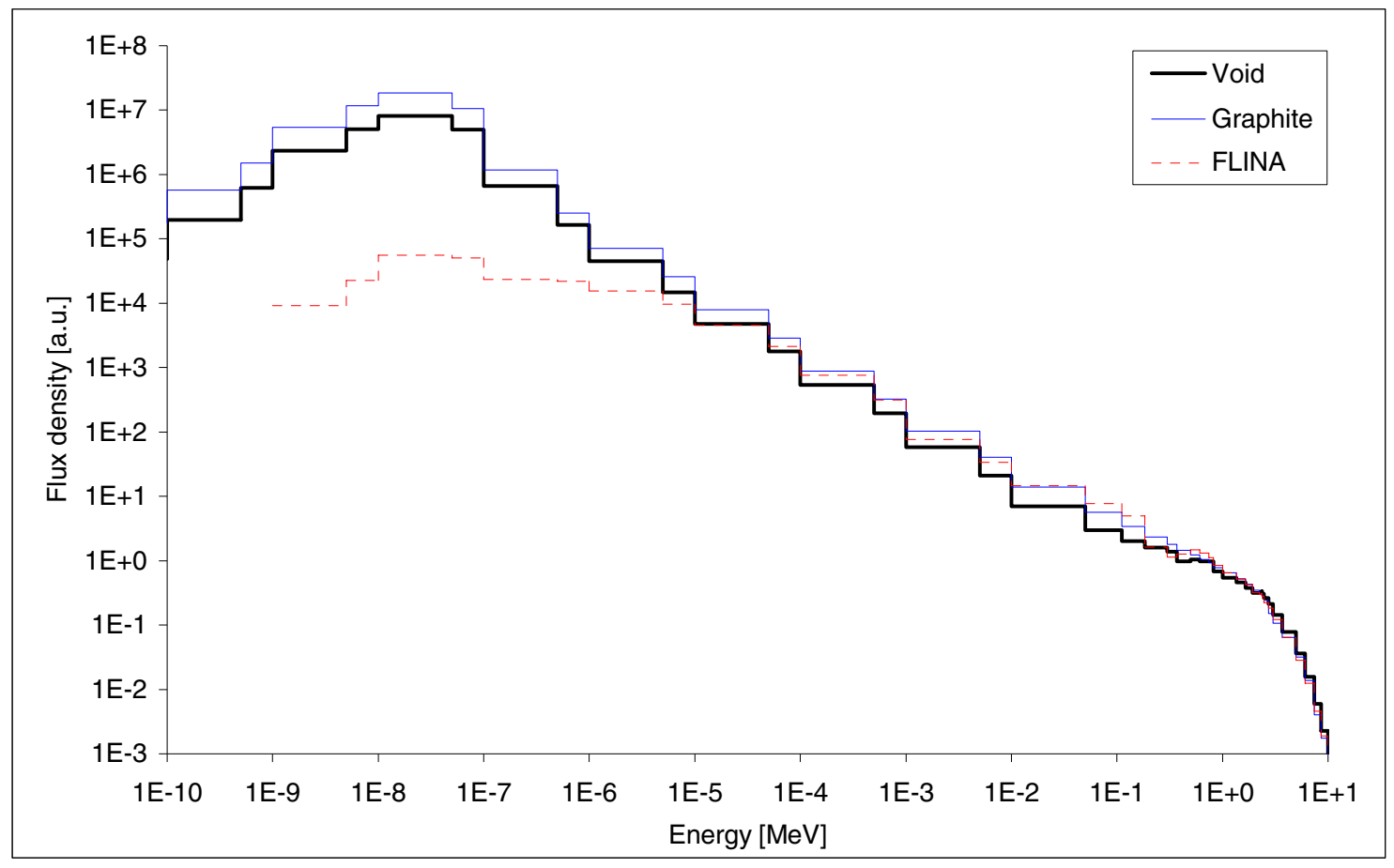

Figure 5.: Comparison of neutron spectra normalized to 1 in integral $>1 \mathrm{MeV}$

\subsection{Calculation methods}

The simulations were performed using the MCNP6 Monte Carlo code Pellowitz 2013 at the experimentally determined moderator height with selected nuclear data libraries: ENDF/BVII, JEFF-3.1, JENDL-4, JENDL-3.3, ROSFOND-2010 and CENDL 3.1. Nuclear data libraries were processed using the NJOY code (Mac Farlane 1994). Good agreement of calculated $k_{\text {eff }}$ with critical value (1.000) was obtained indicating that the fission source uncertainty has only a minor role in the spectra results (in ENDF/B-VII $\mathrm{k}_{\text {eff }}$ are 1.002 for void geometry, 1.001 for graphite and 0.998 for salt insertion with the uncertainties about 0.002). Additional results comparing the various libraries can be found in Kostal et al 2014. The calculated uncertainties of fluxes in wide groups are, in all cases, below $2 \%$, in narrow groups (neutron spectra in linear division per $0.1 \mathrm{MeV}$ ) below 1-2\% in lower regions and below $8 \%$ in high energy regions. 


\section{Results}

\subsection{Neutron flux densities in wide groups}

Figure 6 shows a comparison of the experimentally determined and calculated spectra for the void channel, Figure 7 for experimental and calculated spectra in graphite and Figure 8 for experimental and calculated spectra in FLINA salt. The fluxes are listed in Table 1 for the voided case, in Table 2 for graphite and in Table 3 for FLINA.

The presented spectra are combinations of proportional counter results and Stilbene measurements. The Stilbene results are over 1.2 MeV and the proportional counter are below $1.3 \mathrm{MeV}$. The interval of 1.2 to $1.3 \mathrm{MeV}$ is used for normalization of results. The final spectra are normalized to 1 in integral 1 to $10 \mathrm{MeV}$.

For the experiment, the statistical uncertainties along with the uncertainties of calibration and uncertainty in detector resolution are in the range of $5 \%$ below $5 \mathrm{MeV}$, about $5-8 \%$ in 5 to $8 \mathrm{MeV}$ and reach $10 \%$ in the energy region above $8 \mathrm{MeV}$.

For a comparison of the experiment and the calculation more sources of uncertainty have to be taken into consideration; in addition to the previously mentioned experimental uncertainties and statistical MCNP uncertainty, there are also uncertainties in material description of fuel and insertion. For narrow groups the combined uncertainty in lower energy regions is $5-10 \%$ and in higher ones $10-15 \%$

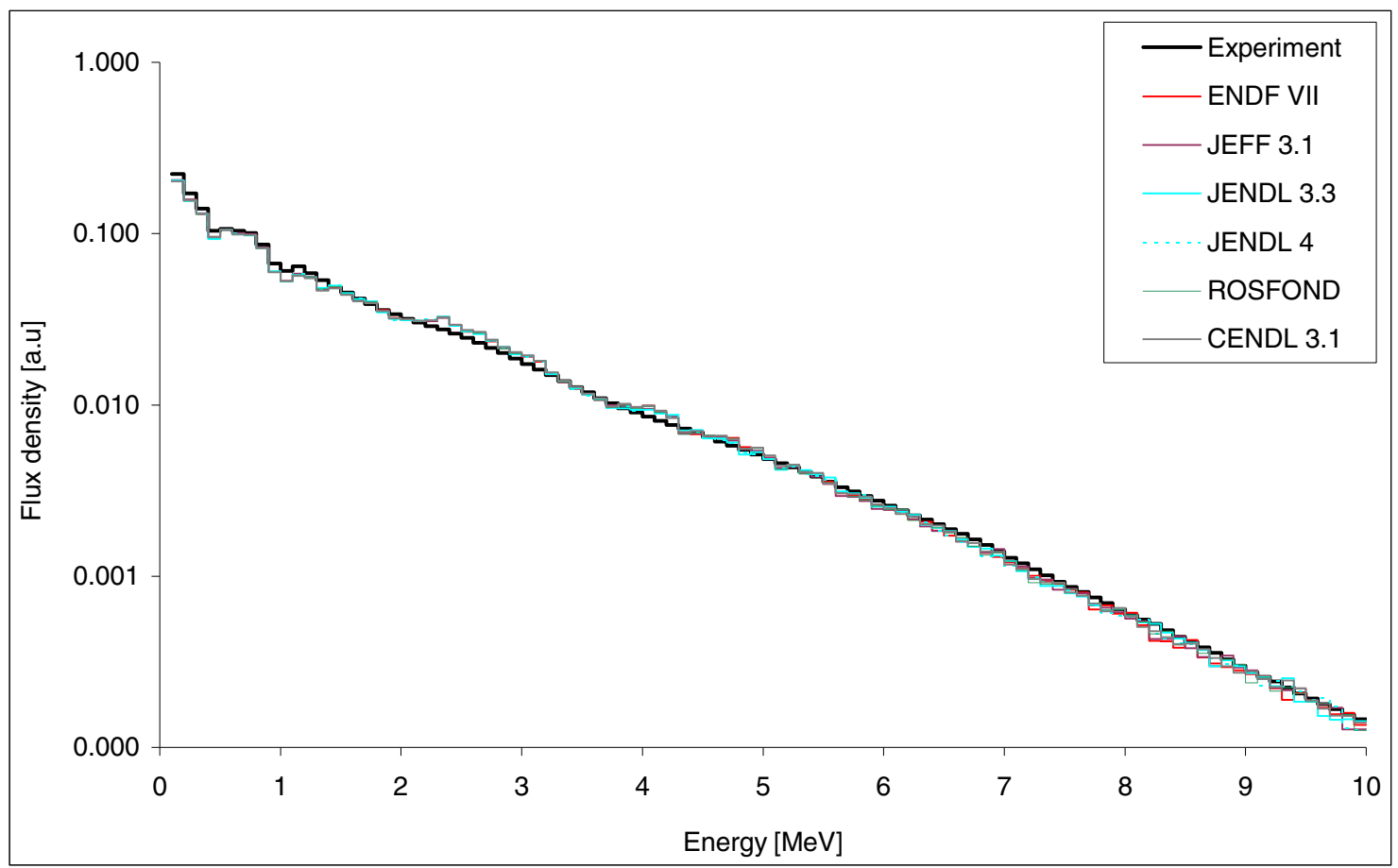

Figure 6.: Neutron spectra in void channel

Table 1.: C/E-1 comparison of neutron flux density in void channel

\begin{tabular}{l|c|c|c|c|c|c|c} 
& $\begin{array}{l}\text { ENDF/B- } \\
\text { VII }\end{array}$ & JEFF-3.1 & JENDL-3.3 & JENDL-4 & $\begin{array}{l}\text { ROSFOND- } \\
2010\end{array}$ & CENDL-3.1 & Uncertainty \\
\hline $0.1-1$ & $-6.8 \%$ & $-5.6 \%$ & $-6.8 \%$ & $-6.7 \%$ & $-6.8 \%$ & $-6.8 \%$ & $3.9 \%$ \\
$1-2$ & $-5.3 \%$ & $-5.2 \%$ & $-5.2 \%$ & $-5.0 \%$ & $-5.6 \%$ & $-6.6 \%$ & $3.8 \%$ \\
$2-3$ & $8.3 \%$ & $8.1 \%$ & $8.3 \%$ & $8.7 \%$ & $8.4 \%$ & $9.3 \%$ & $3.7 \%$ \\
$3-4$ & $2.9 \%$ & $3.4 \%$ & $2.5 \%$ & $2.2 \%$ & $3.4 \%$ & $4.4 \%$ & $4.4 \%$
\end{tabular}




\begin{tabular}{l|c|c|c|c|c|c|c}
$4-5$ & $6.0 \%$ & $5.1 \%$ & $4.6 \%$ & $3.4 \%$ & $6.2 \%$ & $7.1 \%$ & $5.1 \%$ \\
$5-6$ & $-2.0 \%$ & $-3.9 \%$ & $-1.1 \%$ & $-1.9 \%$ & $-2.2 \%$ & $-0.6 \%$ & $6.0 \%$ \\
$6-7$ & $-6.3 \%$ & $-5.7 \%$ & $-4.0 \%$ & $-6.2 \%$ & $-5.1 \%$ & $-4.1 \%$ & $6.9 \%$ \\
$7-8$ & $-6.1 \%$ & $-6.2 \%$ & $-8.1 \%$ & $-8.4 \%$ & $-7.3 \%$ & $-7.2 \%$ & $8.1 \%$ \\
$8-9$ & $-8.8 \%$ & $-7.3 \%$ & $-2.9 \%$ & $-5.2 \%$ & $-4.3 \%$ & $-6.7 \%$ & $9.4 \%$ \\
$9-10$ & $-4.5 \%$ & $-2.7 \%$ & $-3.9 \%$ & $-2.0 \%$ & $-5.3 \%$ & $-1.1 \%$ & $11.5 \%$
\end{tabular}

As expected the calculations are in satisfactory agreement with experiment in case of void channel. Various library results are in quite good agreement between each other. Some discrepancies can be found in the upper energy region. Additionally, some systematic under prediction (see Table 1) in the low energy region, although comparable with uncertainties, can be observed. This effect is most probably caused by poor separation between gamma and neutrons in the region near $1 \mathrm{MeV}$.

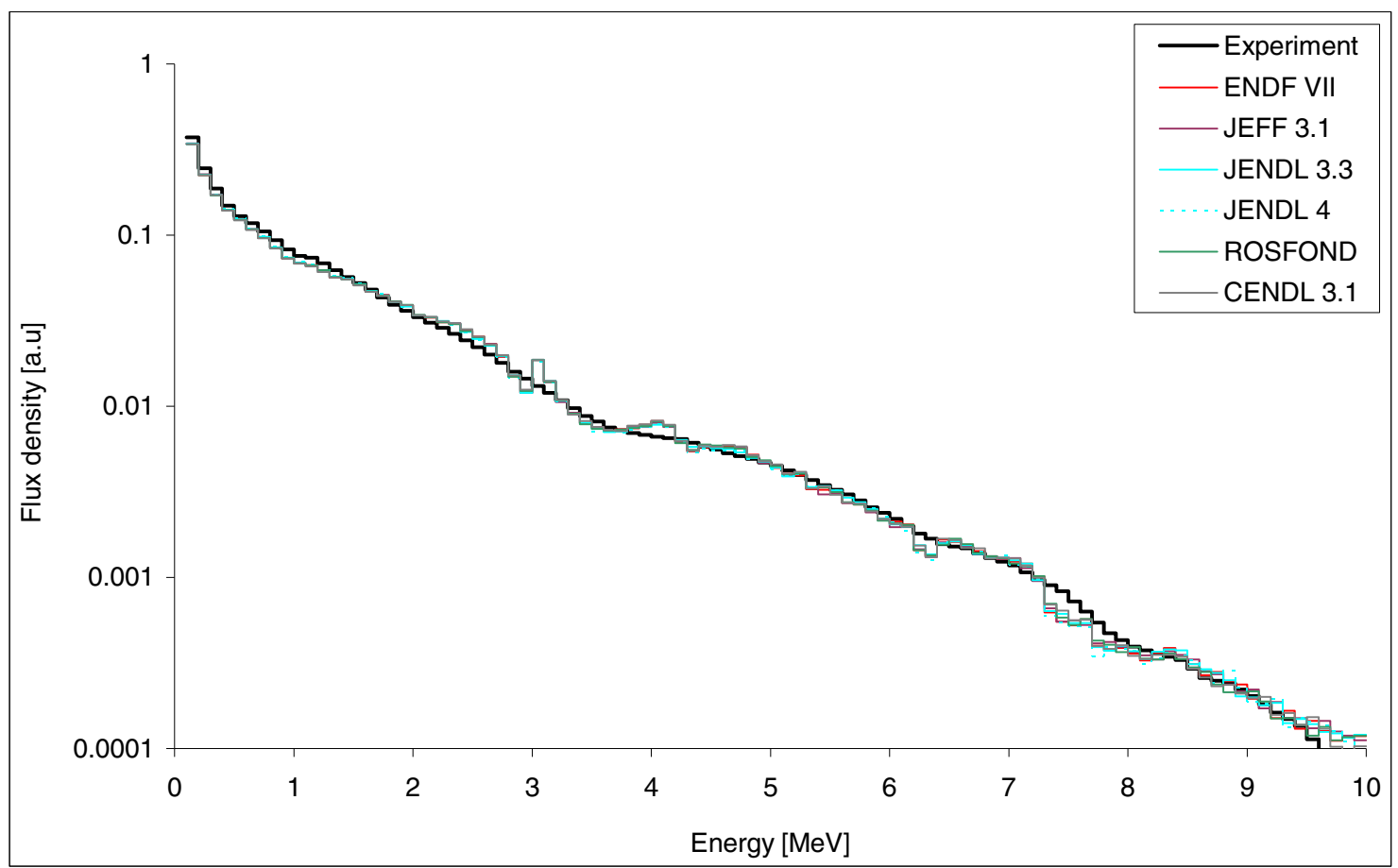

Figure 7.: Neutron spectra in graphite

Table 2.: C/E-1 comparison of neutron flux in graphite

\begin{tabular}{l|c|c|c|c|c|c|c} 
& $\begin{array}{l}\text { ENDF/B- } \\
\text { VII }\end{array}$ & JEFF-3.1 & JENDL-3.3 & JENDL-4 & $\begin{array}{l}\text { ROSFOND- } \\
2010\end{array}$ & CENDL-3.1 & Uncertainty \\
\hline $0.1-1$ & $-8.2 \%$ & $-7.5 \%$ & $-7.7 \%$ & $-7.6 \%$ & $-8.5 \%$ & $-8.7 \%$ & $4.2 \%$ \\
$1-2$ & $-4.3 \%$ & $-4.2 \%$ & $-4.2 \%$ & $-3.2 \%$ & $-4.3 \%$ & $-5.2 \%$ & $4.0 \%$ \\
$2-3$ & $7.2 \%$ & $7.3 \%$ & $7.1 \%$ & $6.2 \%$ & $7.3 \%$ & $8.5 \%$ & $4.2 \%$ \\
$3-4$ & $7.1 \%$ & $6.7 \%$ & $6.6 \%$ & $4.7 \%$ & $6.6 \%$ & $7.7 \%$ & $5.1 \%$ \\
$4-5$ & $6.1 \%$ & $5.5 \%$ & $4.7 \%$ & $3.2 \%$ & $6.1 \%$ & $7.1 \%$ & $6.1 \%$ \\
$5-6$ & $-5.5 \%$ & $-5.9 \%$ & $-3.4 \%$ & $-3.6 \%$ & $-4.7 \%$ & $-4.0 \%$ & $7.2 \%$ \\
$6-7$ & $-2.3 \%$ & $-4.0 \%$ & $-3.0 \%$ & $-4.2 \%$ & $-2.7 \%$ & $-2.2 \%$ & $8.4 \%$ \\
$7-8$ & $-11 \%$ & $-11 \%$ & $-11 \%$ & $-14 \%$ & $-10 \%$ & $-8.5 \%$ & $9.6 \%$ \\
$8-9$ & $2.2 \%$ & $1.7 \%$ & $3.1 \%$ & $1.4 \%$ & $-2.3 \%$ & $-3.2 \%$ & $10.9 \%$
\end{tabular}




\section{\begin{tabular}{l|l|l|l|l|l|l|l}
$9-10$ & $16 \%$ & $23 \%$ & $20 \%$ & $18 \%$ & $17 \%$ & $16 \%$ & $12 \%$
\end{tabular}}

The spectra measured in graphite insertion, especially at higher energies are in good agreement with calculation. All three inflections (see Figure 7) at $3.5 \mathrm{MeV}, 6 \mathrm{MeV}$ and $8 \mathrm{MeV}$ determined by means of experiment occurs in all library results. They are reflecting the wide peaks of the ${ }^{12} \mathrm{C}$ cross section. Comparable character of measured spectra can be found in Olah et al 1999 and also in Makarious et al 1996. Some variations between the nuclear data libraries results can be found in higher energy regions. Slight underestimation of the experiment in the lower energy region, comparable with previous case, can be observed, which is once again attributed to poor separation between gamma and neutrons or apparatus noises near $1 \mathrm{MeV}$. Nevertheless the agreement is still satisfactory.

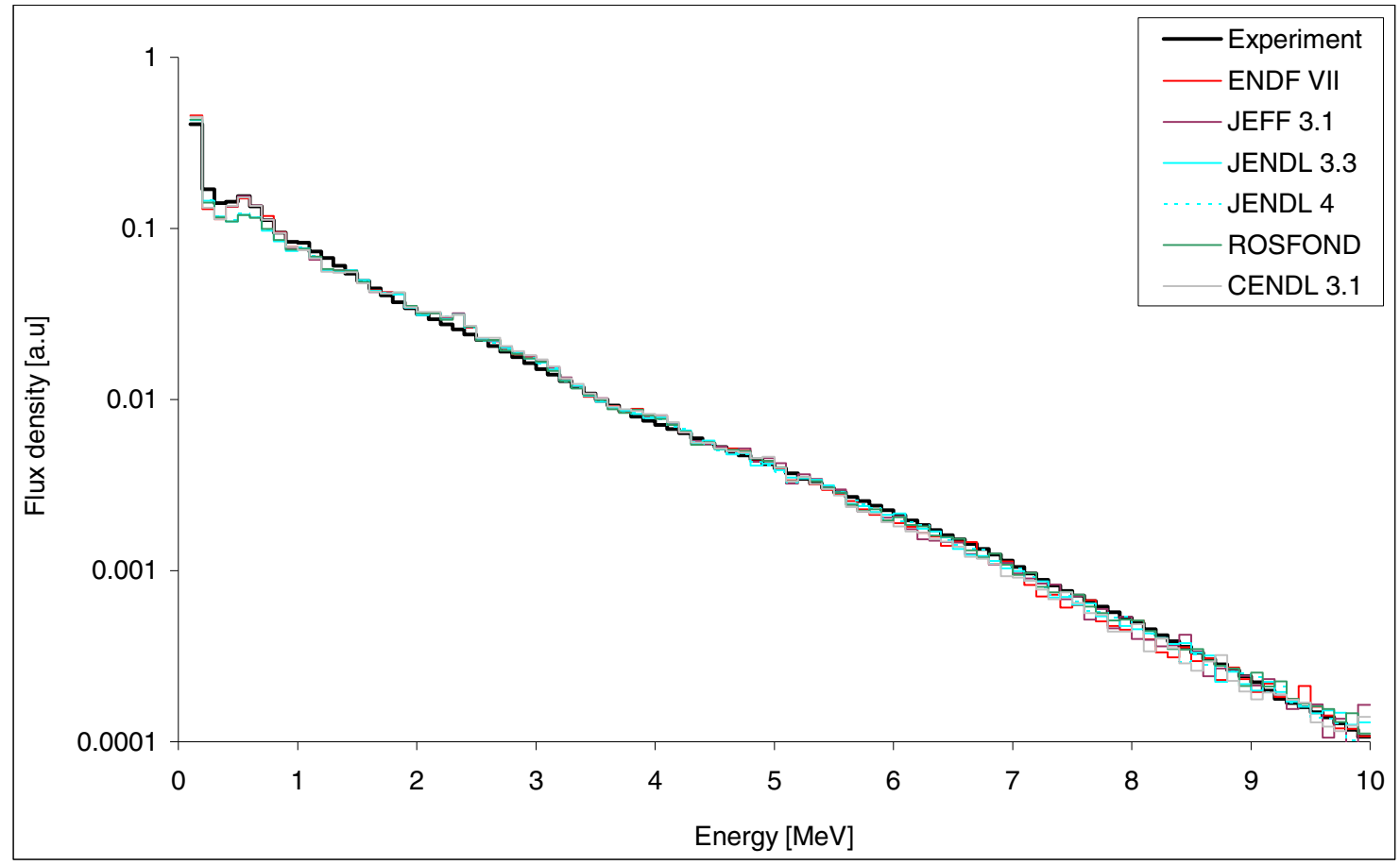

Figure 8.: Neutron spectra in FLINA salt

Table 3.: C/E-1 comparison of neutron flux in FLINA

\begin{tabular}{l|c|c|c|c|c|c|c} 
& $\begin{array}{l}\text { ENDF/B- } \\
\text { VII }\end{array}$ & JEFF-3.1 & JENDL-3.3 & JENDL-4 & ROSFOND- & & \\
& 2010 & CENDL-3.1 & Uncertainty \\
\hline $0.1-1$ & $-1.9 \%$ & $-1.4 \%$ & $-10.1 \%$ & $-9.4 \%$ & $-10.0 \%$ & $-2.6 \%$ & $3.9 \%$ \\
$1-2$ & $-3.4 \%$ & $-4.0 \%$ & $-3.4 \%$ & $-3.2 \%$ & $-3.4 \%$ & $-5.0 \%$ & $3.7 \%$ \\
$2-3$ & $7.5 \%$ & $7.3 \%$ & $7.6 \%$ & $7.6 \%$ & $7.2 \%$ & $10 \%$ & $3.5 \%$ \\
$3-4$ & $2.9 \%$ & $5.6 \%$ & $2.2 \%$ & $1.8 \%$ & $2.3 \%$ & $5.8 \%$ & $3.8 \%$ \\
$4-5$ & $3.2 \%$ & $3.7 \%$ & $1.4 \%$ & $0.5 \%$ & $2.2 \%$ & $3.6 \%$ & $4.2 \%$ \\
$5-6$ & $-4.8 \%$ & $-3.8 \%$ & $-2.4 \%$ & $-2.6 \%$ & $-3.8 \%$ & $-5.5 \%$ & $4.7 \%$ \\
$6-7$ & $-7.6 \%$ & $-8.2 \%$ & $-6.0 \%$ & $-5.6 \%$ & $-4.1 \%$ & $-12 \%$ & $5.4 \%$ \\
$7-8$ & $-13.6 \%$ & $-8.7 \%$ & $-8.6 \%$ & $-6.8 \%$ & $-5.7 \%$ & $-12 \%$ & $6.4 \%$ \\
$8-9$ & $-8.0 \%$ & $-9.8 \%$ & $-4.1 \%$ & $-4.7 \%$ & $-2.2 \%$ & $-10 \%$ & $8.3 \%$ \\
$9-10$ & $4.3 \%$ & $3.8 \%$ & $5.5 \%$ & $0.2 \%$ & $11.1 \%$ & $-2.0 \%$ & $10 \%$
\end{tabular}


The FLINA is the case where the most notable differences between experiment and calculation can be found. An interesting observation is the notable variations between the different nuclear data libraries in the low energy region seen in Figure 8. Looking at Table 3 in the 0.1 to $1 \mathrm{MeV}$ range, the calculation underestimates experiment by $2 \%$ using ENDF/BVII and as much as $10 \%$ using JENDL-4. Although optimistic, the ENDF/B-VII results overestimate the flux in the 0.1 to $0.2 \mathrm{MeV}$ range by $13 \%$ and underestimate the 0.2 to $1.0 \mathrm{MeV}$ range by $8 \%$.

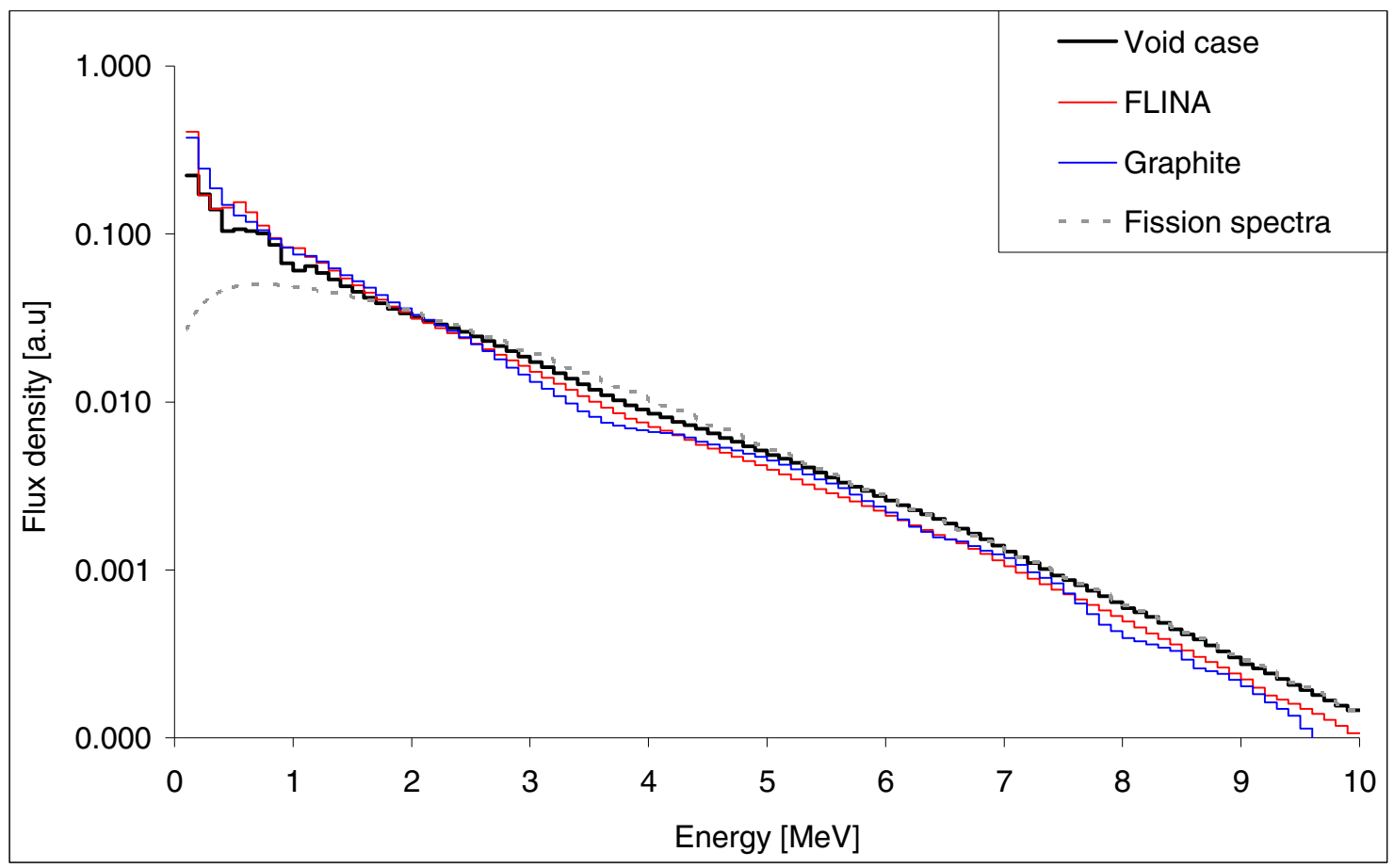

Figure 9.: Neutron fluxes in various insertions

Table 4.: Measured neutron spectra in various insertions

\begin{tabular}{|c|c|c|c|c|c|c|}
\hline & $\begin{array}{l}\text { Void } \\
\text { Flux } \\
\text { [a.u.] }\end{array}$ & Uncertainty & $\begin{array}{l}\text { FLINA } \\
\text { Flux [a.u.] }\end{array}$ & Uncertainty & \begin{tabular}{|l} 
GRAPHIT \\
Flux \\
[a.u.]
\end{tabular} & Uncertainty \\
\hline $0.1-1$ & $1.103 \mathrm{E}+0$ & $3.9 \%$ & $1.440 \mathrm{E}+0$ & $3.9 \%$ & $1.483 E+0$ & $4.2 \%$ \\
\hline $1-2$ & $4.813 \mathrm{E}-1$ & $3.8 \%$ & $5.440 \mathrm{E}-1$ & $3.7 \%$ & $5.557 \mathrm{E}-1$ & $4.0 \%$ \\
\hline $2-3$ & $2.524 \mathrm{E}-1$ & $3.7 \%$ & $2.341 \mathrm{E}-1$ & $3.4 \%$ & $2.338 \mathrm{E}-1$ & $4.2 \%$ \\
\hline $3-4$ & $1.263 \mathrm{E}-1$ & $4.4 \%$ & $1.078 \mathrm{E}-1$ & $3.8 \%$ & $9.118 \mathrm{E}-2$ & $5.1 \%$ \\
\hline $4-5$ & 6.737E-2 & $5.1 \%$ & $5.530 \mathrm{E}-2$ & $4.2 \%$ & $5.716 \mathrm{E}-2$ & $6.1 \%$ \\
\hline $5-6$ & 3.730E-2 & $6.0 \%$ & 3.014E-2 & $4.6 \%$ & 3.391E-2 & $7.2 \%$ \\
\hline $6-7$ & 1.963E-2 & $6.9 \%$ & 1.594E-2 & $5.3 \%$ & $1.615 \mathrm{E}-2$ & $8.3 \%$ \\
\hline $7-8$ & $9.274 \mathrm{E}-3$ & $8.0 \%$ & 7.579E-3 & $6.2 \%$ & 7.745E-3 & $9.5 \%$ \\
\hline $8-9$ & $4.383 \mathrm{E}-3$ & $9.3 \%$ & 3.532E-3 & $7.9 \%$ & 3.062E-3 & $10.7 \%$ \\
\hline $9-10$ & $2.046 \mathrm{E}-3$ & $11.3 \%$ & $1.567 \mathrm{E}-3$ & $9.7 \%$ & $1.235 \mathrm{E}-3$ & $11.4 \%$ \\
\hline
\end{tabular}

Comparison between all measured spectra plotted in Figure 9 shows that both graphite and FLINA slow down neutrons effectively with graphite being slightly better. In the case of 
FLINA, in the lowest 0.1 to $1 \mathrm{MeV}$ group, flux increases by $31 \%$ over the void case, while in graphite it increases by $35 \%$. The shape of spectra reflects the slowing down properties, while the absorbing properties of various insertions are reflected in various critical levels. In void case the moderator critical height is $55.6 \mathrm{~cm}$. The graphite has very low cross section, thus when graphite insertion is used, the critical moderator level is lower than in void case, namely $43.221 \mathrm{~cm}$. FLINA is strong absorber. When used, the moderator critical level increases to $80.255 \mathrm{~cm}$. It means that in FLINA case the water level is higher than the FLINA capsule.

Table 5.: Calculated $\mathrm{k}_{\mathrm{eff}}$ for various arrangements in various libraries

\begin{tabular}{c|ccccccc} 
& ENDF & \multicolumn{3}{c}{ JENDL } & & \multicolumn{3}{c}{ CENDL } & \\
& VII & JEFF 3.1 & 3.3 & JENDL 4 & ROSFOND & 3.1 & Uncertainty \\
\hline Void & 1.00183 & 1.00050 & 0.99908 & 1.00138 & 1.00077 & 1.00053 & 0.00208 \\
Graphite & 1.00134 & 0.9999 & 0.99859 & 1.00056 & 1.00022 & 0.99998 & 0.00186 \\
FLINA & 0.99877 & 0.99743 & 0.99587 & 0.99818 & 0.99769 & 0.99724 & 0.00220
\end{tabular}

\subsection{Neutron flux densities in smooth structure}

As mentioned above, the previous comparisons where performed by normalizing the proportional counter and Stilbene results using overlapping 1.2 to $1.3 \mathrm{MeV}$ energy range. This could result in systematic overestimation. Thus, the analysis was also performed by comparing the proportional counter results normalized to calculation in the interval 0.1 $1 \mathrm{MeV}$. The comparison between calculation and measurement is realized by means of C/E-1 ratio using a smooth structure of 40 groups per decade. The experimental results are plotted in Figure 10. The spectrum in graphite is quite smooth structure, while FLINA and Void cases have peaks. These peaks are caused by the fine structure of materials forming FLINA and also structural materials, like aluminum used to clad the void channel 


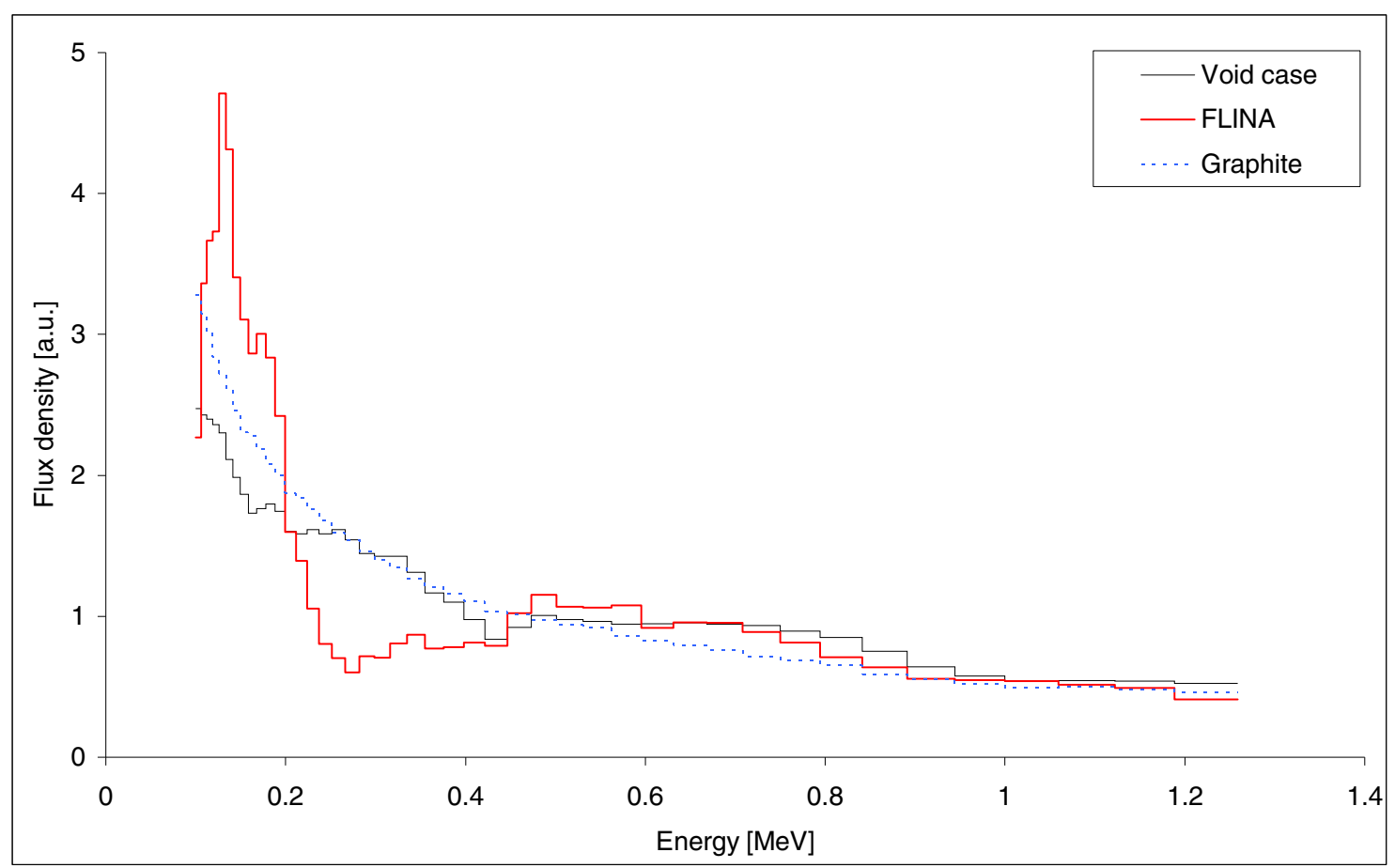

Figure 10.: Measured spectra normalized to 1 in interval 0.1-1 MeV

In the case of the void channel (see Figure 11), the calculation to experiment ratio (C/E-1 hereafter) oscillates between $-10 \%$ and $10 \%$. The discrepancies are most probably caused by insufficient resolution of the detector which manifests itself in the peaks of the spectrum.

In the case of graphite the agreement is better as (see Figure 12), the reason being the smoother nature of the cross-section over this energy range.

Notable variations can be found in the case of the FLINA insertion as illustrated in Figure 13. Part of the effect might be on account of the poor resolution, but the rate of underestimation in 0.3 to $0.5 \mathrm{MeV}$ is in many cases higher than the uncertainties $(3-4 \%)$. Additionally, strong variations are observed when comparing the JENDL-3.3 and ENDF/B-VII libraries. JENDL results in the 0.2 to $0.3 \mathrm{MeV}$ region have a discrepancy of about $5 \%$ while ENDF/B-VII is nearly $21 \%$. Similar trends are also observed in the 0.9 to $1.3 \mathrm{MeV}$ region.

Generally the results agree with those presented by Kato et al 2014. 


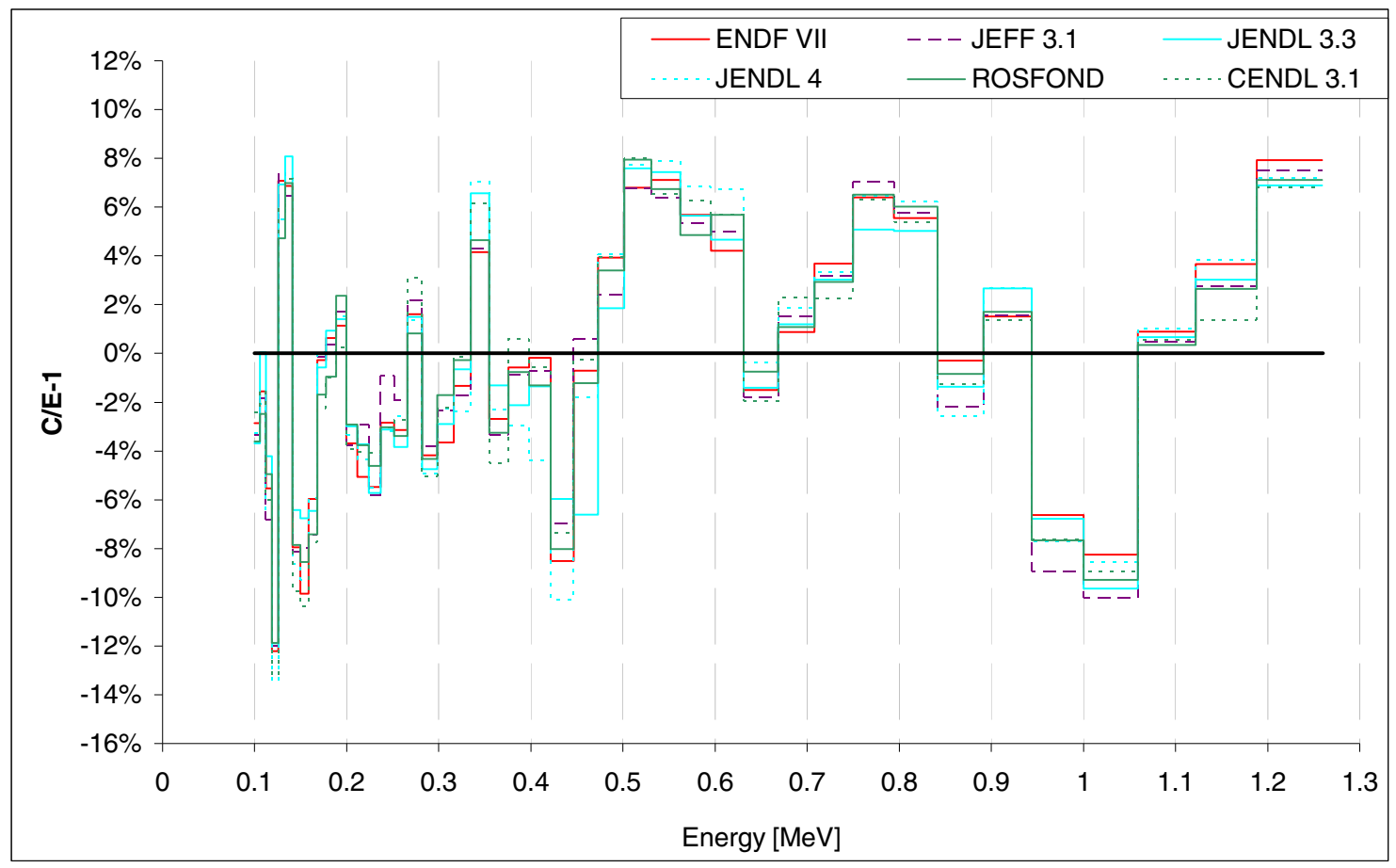

Figure 11.: C/E-1 in low energy region in void channel

Table 6.: C/E-1 of neutron flux densities in void channel and low energy region

\begin{tabular}{|c|c|c|c|c|c|c|c|c|}
\hline & $\begin{array}{l}\text { Experime } \\
\text { Flux } \\
\text { [a.u.] }\end{array}$ & Uncertainty & $\begin{array}{l}\text { ENDF/B- } \\
\text { VII }\end{array}$ & $\begin{array}{l}\text { JEFF- } \\
3.1\end{array}$ & $\begin{array}{l}\text { JENDL- } \\
3.3\end{array}$ & $\begin{array}{l}\text { C/E-1 } \\
\text { JENDL- } \\
4\end{array}$ & ROSFOND-2010 & $\begin{array}{l}\text { CENDL- } \\
3.1\end{array}$ \\
\hline 0.1 & 0.202 & $2.8 \%$ & $-2.2 \%$ & $-2.2 \%$ & $-1.5 \%$ & $-2.5 \%$ & $-2.6 \%$ & $-3.0 \%$ \\
\hline 0.2 & 0.156 & $2.7 \%$ & $-3.0 \%$ & $-2.2 \%$ & $-3.1 \%$ & $-3.1 \%$ & $-2.8 \%$ & $-2.6 \%$ \\
\hline 0.3 & 0.127 & $3.5 \%$ & $-0.7 \%$ & $-0.7 \%$ & $0.0 \%$ & $-0.5 \%$ & $-0.3 \%$ & $0.1 \%$ \\
\hline 0.4 & 0.0942 & $4.3 \%$ & $-2.0 \%$ & $-1.9 \%$ & $-3.8 \%$ & $-3.5 \%$ & $-2.3 \%$ & $-1.6 \%$ \\
\hline 0.5 & 0.0965 & $3.3 \%$ & $5.9 \%$ & $5.5 \%$ & $6.3 \%$ & $6.8 \%$ & $6.0 \%$ & $6.4 \%$ \\
\hline 0.6 & 0.0940 & $2.7 \%$ & $2.0 \%$ & $2.6 \%$ & $2.3 \%$ & $3.8 \%$ & $2.8 \%$ & $2.7 \%$ \\
\hline 0.7 & 0.0914 & $3.1 \%$ & $4.6 \%$ & $4.7 \%$ & $3.8 \%$ & $4.5 \%$ & $4.3 \%$ & $4.2 \%$ \\
\hline 0.8 & 0.0781 & $2.7 \%$ & $2.9 \%$ & $2.1 \%$ & $2.1 \%$ & $2.4 \%$ & $3.0 \%$ & $2.3 \%$ \\
\hline 0.9 & 0.0606 & $5.3 \%$ & $-3.7 \%$ & $-4.9 \%$ & $-3.1 \%$ & $-3.8 \%$ & $-4.2 \%$ & $-4.3 \%$ \\
\hline 1 & 0.0548 & $4.3 \%$ & $-5.9 \%$ & $-7.1 \%$ & $-6.4 \%$ & $-5.9 \%$ & $-6.7 \%$ & $-6.1 \%$ \\
\hline 1.1 & 0.0583 & $2.8 \%$ & $-3.8 \%$ & $-4.1 \%$ & $-4.4 \%$ & $-3.5 \%$ & $-4.5 \%$ & $-5.4 \%$ \\
\hline 1.2 & 0.0533 & $2.7 \%$ & $2.1 \%$ & $1.0 \%$ & $1.3 \%$ & $1.4 \%$ & $1.5 \%$ & $0.4 \%$ \\
\hline
\end{tabular}




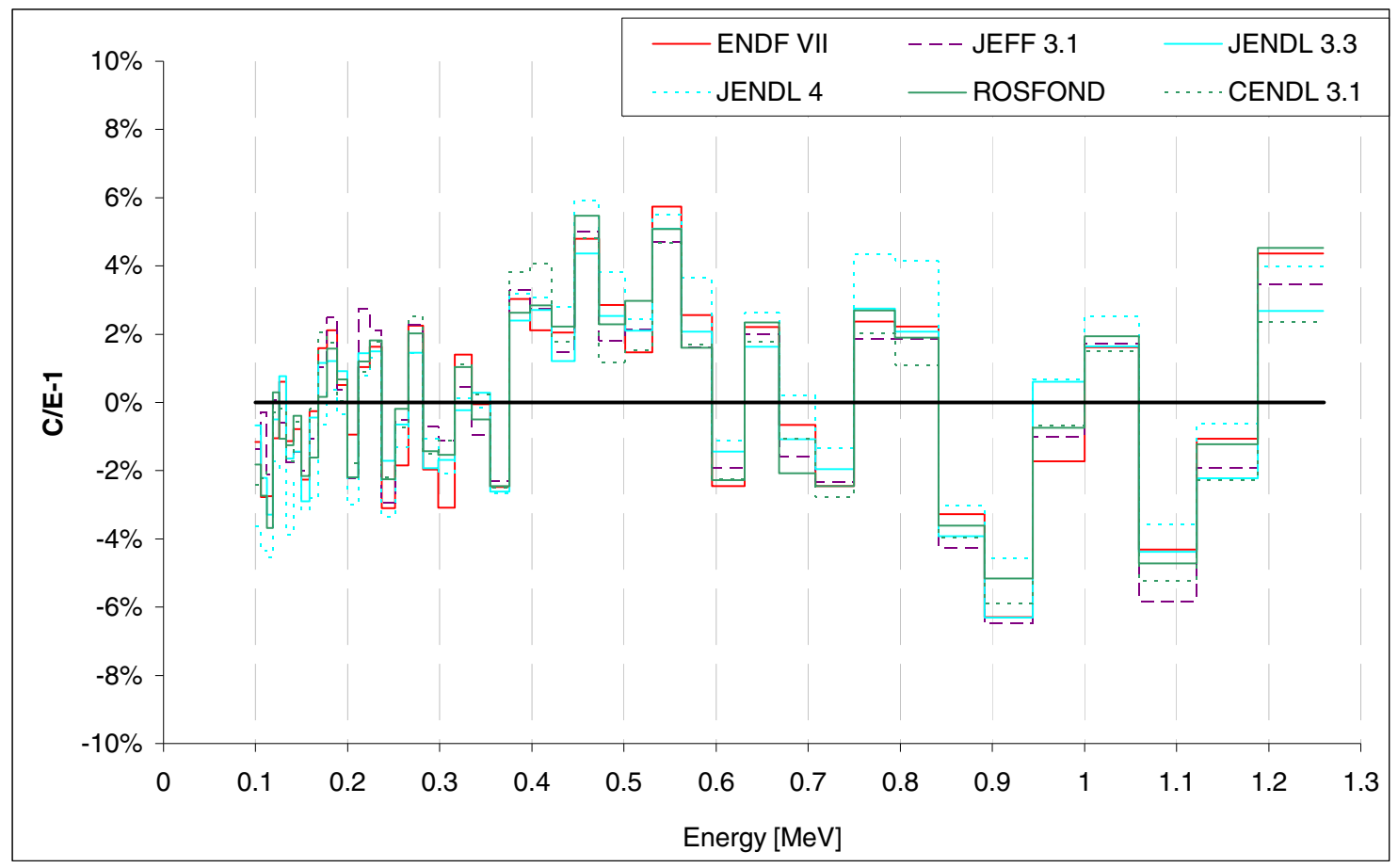

Figure 12.: C/E-1 in low energy region in graphite

Table 7.: C/E-1 of neutron flux densities in graphite and low energy region

\begin{tabular}{|c|c|c|c|c|c|c|c|c|}
\hline & \multicolumn{2}{|c|}{\begin{tabular}{|l} 
Experiment \\
Flux
\end{tabular}} & \begin{tabular}{|l} 
ENDF/B- \\
VII
\end{tabular} & $\begin{array}{l}\text { JEFF- } \\
3.1\end{array}$ & $\begin{array}{l}\text { JENDL- } \\
3.3\end{array}$ & $\begin{array}{l}\text { C/E-1 } \\
\text { JENDL- } \\
4\end{array}$ & ROSFOND-2010 & $\begin{array}{l}\text { CENDL- } \\
3.1\end{array}$ \\
\hline 0.1 & 0.251 & $4.0 \%$ & $-0.4 \%$ & $-0.3 \%$ & $-0.5 \%$ & $-2.2 \%$ & $-0.7 \%$ & $-0.4 \%$ \\
\hline 0.2 & 0.165 & $2.6 \%$ & $-0.5 \%$ & $0.1 \%$ & $-0.3 \%$ & $-0.8 \%$ & $-0.3 \%$ & $-0.2 \%$ \\
\hline 0.3 & 0.126 & $2.7 \%$ & $-0.4 \%$ & $-0.4 \%$ & $-0.6 \%$ & $-0.5 \%$ & $-0.4 \%$ & $0.1 \%$ \\
\hline 0.4 & 0.1006 & $2.6 \%$ & $2.3 \%$ & $2.1 \%$ & $2.0 \%$ & $3.3 \%$ & $2.6 \%$ & $2.3 \%$ \\
\hline 0.5 & 0.0871 & $2.7 \%$ & $3.8 \%$ & $3.5 \%$ & $3.8 \%$ & $4.6 \%$ & $3.7 \%$ & $3.2 \%$ \\
\hline 0.6 & 0.0795 & $2.7 \%$ & $-0.1 \%$ & $-0.5 \%$ & $-0.1 \%$ & $0.6 \%$ & $-0.2 \%$ & $-0.3 \%$ \\
\hline 0.7 & 0.0710 & $2.8 \%$ & $-0.1 \%$ & $-0.1 \%$ & $0.4 \%$ & $1.5 \%$ & $-0.1 \%$ & $-0.4 \%$ \\
\hline 0.8 & 0.0629 & $2.8 \%$ & $-1.1 \%$ & $-1.9 \%$ & $-1.7 \%$ & $-0.2 \%$ & $-1.4 \%$ & $-2.0 \%$ \\
\hline 0.9 & 0.0558 & $4.5 \%$ & $-4.4 \%$ & $-4.1 \%$ & $-3.1 \%$ & $-2.2 \%$ & $-3.3 \%$ & $-3.5 \%$ \\
\hline 1 & 0.0509 & $3.7 \%$ & $-1.0 \%$ & $-1.5 \%$ & $-1.1 \%$ & $-0.1 \%$ & $-1.1 \%$ & $-1.3 \%$ \\
\hline 1.1 & 0.0498 & $2.8 \%$ & $-1.5 \%$ & $-2.6 \%$ & $-2.4 \%$ & $-1.2 \%$ & $-1.8 \%$ & $-3.0 \%$ \\
\hline 1.2 & 0.0461 & $2.8 \%$ & $-0.9 \%$ & $-1.6 \%$ & $-1.8 \%$ & $-0.9 \%$ & $-0.5 \%$ & $-2.3 \%$ \\
\hline
\end{tabular}




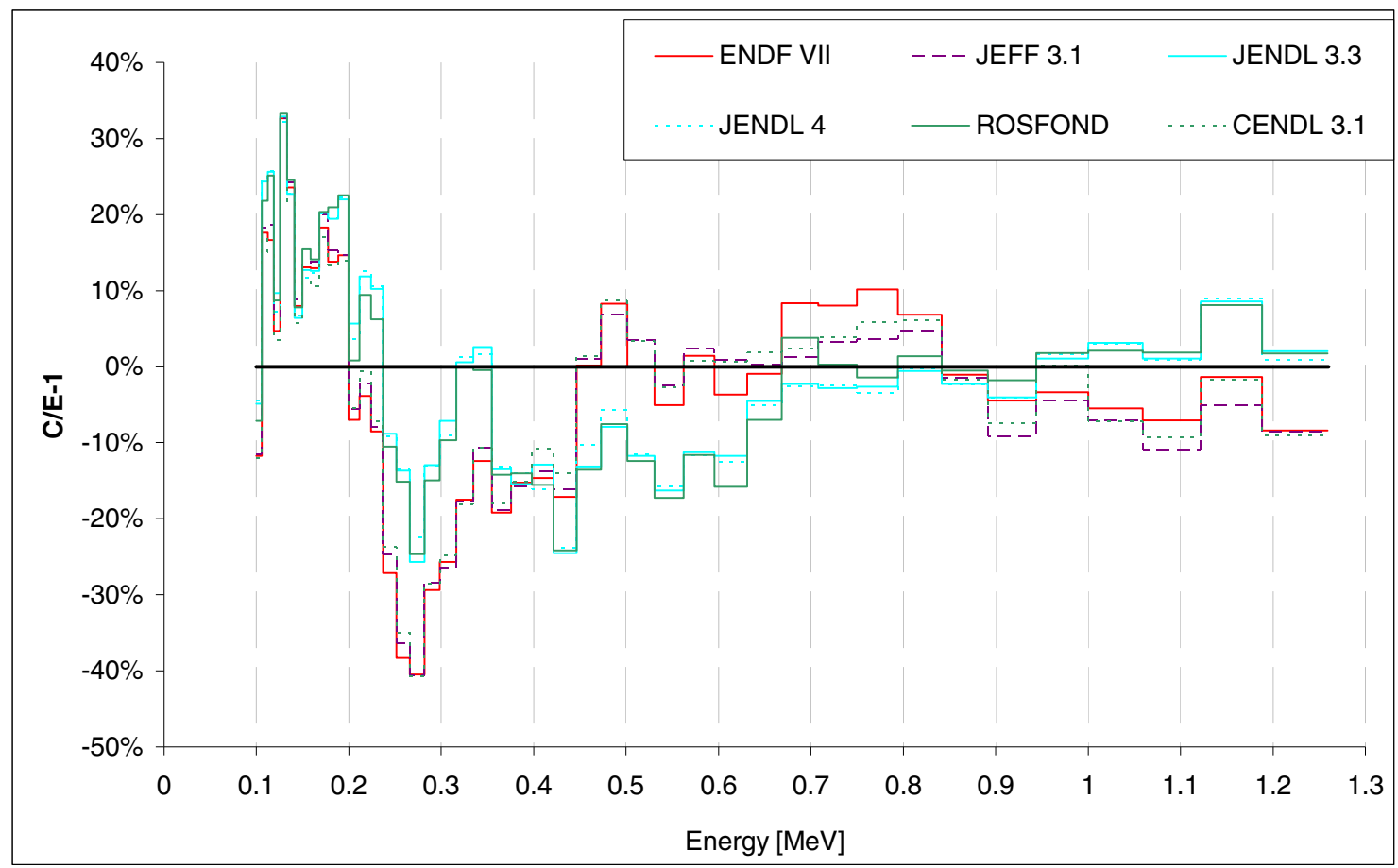

Figure 13.: C/E-1 in low energy region in salt

Table 8.: C/E-1 of neutron flux densities in FLINA and low energy region

\begin{tabular}{|c|c|c|c|c|c|c|c|c|}
\hline & \multicolumn{2}{|c|}{$\begin{array}{l}\text { Experiment } \\
\text { Flux }\end{array}$} & \multicolumn{6}{|c|}{$\mathrm{C} / \mathrm{E}-1$} \\
\hline 0.1 & 0.282 & $3.0 \%$ & $15.1 \%$ & $15.5 \%$ & $18.0 \%$ & $17.7 \%$ & $18.5 \%$ & $13.7 \%$ \\
\hline 0.2 & 0.118 & $6.1 \%$ & $-22.0 \%$ & $-20.9 \%$ & $-4.8 \%$ & $-4.6 \%$ & $-7.1 \%$ & $-20.0 \%$ \\
\hline 0.3 & 0.098 & $3.3 \%$ & $-18.2 \%$ & $-17.6 \%$ & $-7.5 \%$ & $-7.6 \%$ & $-8.7 \%$ & $-17.5 \%$ \\
\hline 0.4 & 0.0998 & $2.8 \%$ & $-5.0 \%$ & $-4.5 \%$ & $-14.9 \%$ & $-14.0 \%$ & $-15.1 \%$ & $-3.2 \%$ \\
\hline 0.5 & 0.1075 & $3.7 \%$ & $-1.3 \%$ & $0.5 \%$ & $-13.4 \%$ & $-13.2 \%$ & $-14.1 \%$ & $0.5 \%$ \\
\hline 0.6 & 0.0936 & $2.7 \%$ & $2.5 \%$ & $3.0 \%$ & $-4.4 \%$ & $-5.0 \%$ & $-5.0 \%$ & $3.4 \%$ \\
\hline 0.7 & 0.0777 & $2.8 \%$ & $7.9 \%$ & $2.8 \%$ & $-3.6 \%$ & $-3.8 \%$ & $-1.2 \%$ & $3.2 \%$ \\
\hline 0.8 & 0.0655 & $3.0 \%$ & $2.8 \%$ & $1.0 \%$ & $-0.9 \%$ & $-0.7 \%$ & $1.0 \%$ & $2.4 \%$ \\
\hline 0.9 & 0.0581 & $4.8 \%$ & $-4.7 \%$ & $-6.2 \%$ & $-1.8 \%$ & $-1.6 \%$ & $-0.4 \%$ & $-4.2 \%$ \\
\hline 1 & 0.0573 & $3.6 \%$ & $-5.1 \%$ & $-8.3 \%$ & $3.3 \%$ & $3.0 \%$ & $2.5 \%$ & $-7.0 \%$ \\
\hline 1.1 & 0.0508 & $2.9 \%$ & $-6.1 \%$ & $-6.9 \%$ & $3.5 \%$ & $3.7 \%$ & $3.7 \%$ & $-6.5 \%$ \\
\hline 1.2 & 0.0468 & $2.9 \%$ & $-13.2 \%$ & $-14.8 \%$ & $-5.3 \%$ & $-5.3 \%$ & $-4.7 \%$ & $-14.7 \%$ \\
\hline
\end{tabular}

The variations between JENDL-3.3 and ENDF/B-VII can be explained by different description of ${ }^{19} \mathrm{~F}$, namely different inelastic to elastic scatter ratio. For detailed cross section plots see Figure 14. The notable increase in inelastic scatter in region 0.4 to $0.6 \mathrm{MeV}$ in JENDL-3.3 reflects in neutron flux decrease in the same region. The loosed neutrons are scattered into the 0.2 to $0.4 \mathrm{MeV}$ region because of the relatively low adopted levels (namely109.89 keV for first and $197.14 \mathrm{keV}$ for second level). Thus in this interval notably higher flux than in ENDF/B-VII case can be observed. 


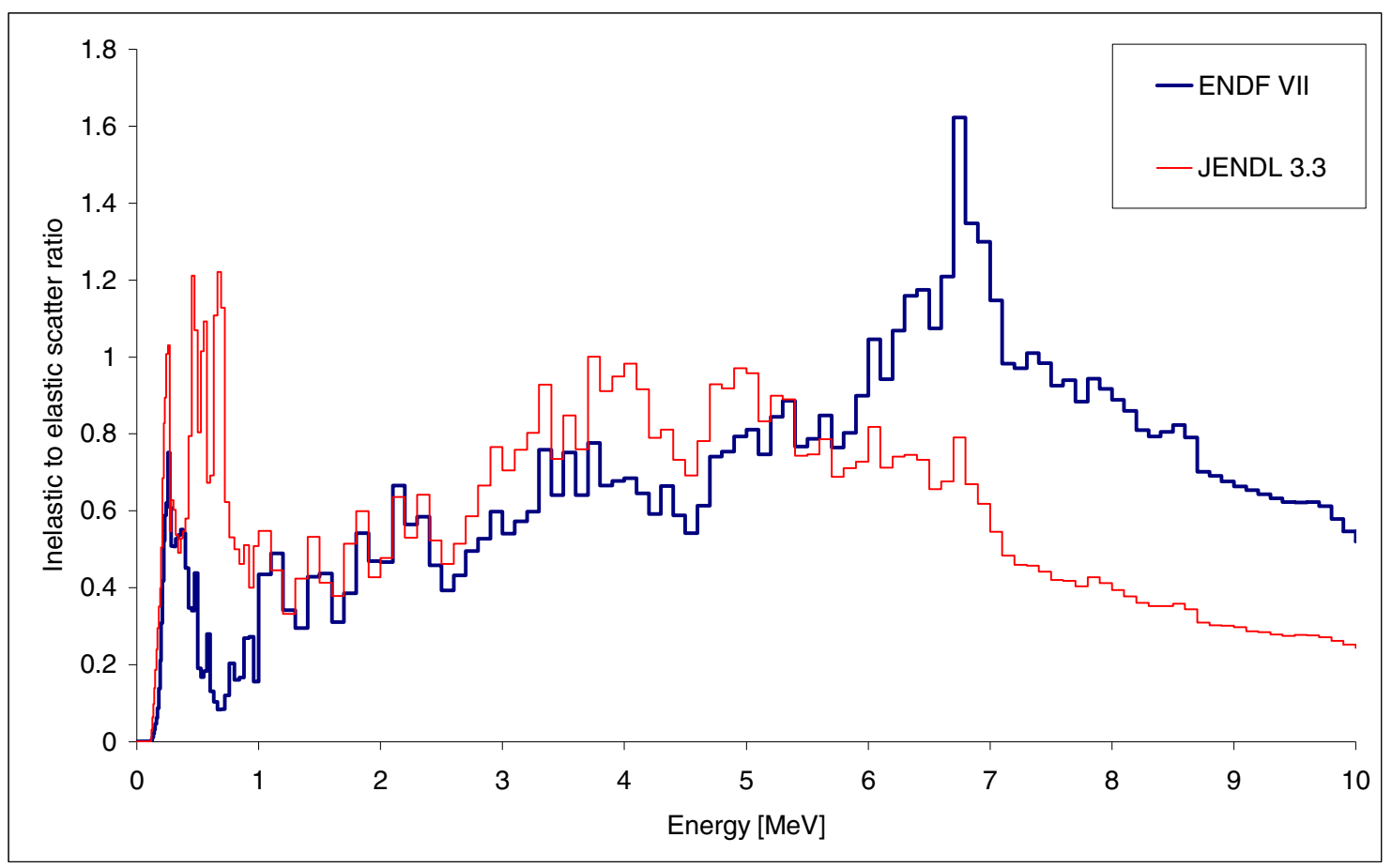

Figure 14.: Inelastic to elastic scatter ratio

\section{Conclusions}

The neutron spectra in arrangements with void, graphite and FLINA salt insertions were measured. The best agreement between experiments and Monte Carlo simulations was obtained for graphite where all nuclear data libraries agree quite well with experiment. This result is not too surprising since graphite is well described due a long history as a nuclear material. The smooth character of its cross section also reduces calculation to experiment discrepancies in the low energy region.

Good agreement was also in the void case. Some discrepancies were found in the low energy region, but they are small and can be attributed to insufficient resolution of the detector. The results of wider group structure fully support this conclusion.

Notable discrepancies are observed with the FLINA capsule where differences as high as $40 \%$ are observed, nearly 10 times more than related uncertainties. Additionally, the various nuclear data libraries differ from each other. The reason is attributed mainly to variations in ${ }^{19} \mathrm{~F}$ evaluations, namely in the inelastic to elastic scatter ratio. The observed trend is comparable to those presented by Kato et al 2014.

\section{Acknowledgements}

These experiments and calculations have been funded by Research Centre Rez Ltd. within Ministry of Education, Youth and Sport Czech Republic project MSM 2672244501, and by SUSEN Project CZ.1.05/2.1.00/03.0108 realized within the framework of the European Regional Development Fund (ERDF) and by Support of mathematical and physical research Cvachovec F. at al 2006. The last two authors would also like to acknowledge support from the MIT UROP program and the DOE NEUP program for partial support of this work. 


\section{References}

CENDL 3.1 Z.G. Ge, Y.X. Zhuang, T.J. Liu, J.S. Zhang, H.C. Wu, Z.X. Zhao, H.H. Xia, The Updated Version of Chinese Evaluated Nuclear Data Library (CENDL-3.1), Proc.

International Conference on Nuclear Data for Science and Technology, Jeju Island, Korea (April 2010), pp. 26-30

Cvachovec J. et al., 2008 J. Cvachovec, F. Cvachovec, Maximum Likelihood Estimation of a Neutron Spectrum and Associated Uncertainties, AiMT, Vol.1, No2, 2008 pp 67 - 79

Cvachovec F. at al 2006 F. Cvachovec, Z. Bures, M. Komarek at all, Support of Mathematical and Physical Research, Final Report of Specific Research in 2006, University of Defence in Brno, pp $2-6$

DOE 2013 http://www.energy.gov/ne/articles/united-states-and-czech-republic-join-togetherannounce-bilateral; http://www.energy.gov/articles/energy-department-completes-saltcoolant-material-transfer-czech-republic-advanced-reactor

ENDF/B-VII M.B. Chadwick, P. Obložinský, M. Herman et al ENDF/B-VII.0: Next Generation Evaluated Nuclear Data Library for Nuclear Science and Technology, Nuclear Data Sheets, Volume 107, Issue 12, December 2006, Pages 2931-3060, ISSN 0090-3752, doi:10.1016/j.nds.2006.11.001

Jansky et al 2014 Bohumil Jansky, Evzen Novak, Neutron spectrometry with spherical hydrogen proportional detectors, Nuclear Instruments and Methods in Physics Research Section A: Accelerators, Spectrometers, Detectors and Associated Equipment, Volume 735, 21 January 2014, Pages 390-398, ISSN 0168-9002, doi:10.1016/j.nima.2013.08.034 JEFF-3.1 A. Koning, R. Forrest, M. Kellett et al., "The JEFF-3.1Nuclear Library, JEFF Report 21," NEA No. 6190 (2006)

JENDL-3.3 K. Shibata, T. Kawano, T. Nakagawa, et al., Japanese Evaluated Nuclear Data Library Version 3 Revision-3: JENDL-3.3, Journal of Nuclear Science and Technology, 39 (2002), p. 1125

JENDL-4 K. Shibata, O. Iwamoto, T. Nakagawa, N. Iwamoto, A. Ichihara, S. Kunieda, S. Chiba, K. Furutaka, N. Otuka, T. Ohsawa, T. Murata, H. Matsunobu, A. Zukeran, S. Kamada, J. Katakura, JENDL-4.0: A new library for nuclear science and engineering, J. Nucl. Sci. Technol., 48 (2011), pp. 1-30

Kato et al 2014 Yoshinari Kato, Kosuke Takakura, Masayuki Ohta, Kentaro Ochiai, Satoshi Sato, Chikara Konno, Benchmark test of JENDL-4.0 with TOF experiments at Osaka Univ./OKTAVIAN, Progress in Nuclear Science and Technology, 4, pp. 317-321 (2014) Kostal et al 2014 Michal Košt’ál, Ján Milčák, Vlastimil Juříček, Evžen Losa, Benoit Forget, Sterling Harper, Neutronic, Study of graphite reactivity worth on well-defined core assembled LR-0 Reactor, will be published

Kyncl et al 2008 J. Kyncl, V. Rypar, E. Novák: LEU-COMP-THERM-087 „VVER Physics Experiments: Hexagonal Lattices (1.22 cm Pitch) of Low Enriched U(3.6, 4.4 wt.\% U235)O Fuel Assemblies in Light Water with Variable Fuel Assemblies Pitch", 2008, NEA/NSC/DOC/(95)03/IV Volume IV

LANL 2003 MCNP-A General Monte Carlo N-Particle Transport Code. Version 5, LA-CP03-0245, X-5 Monte Carlo Team, Los Alamos National Laboratory, Los Alamos, NM, USA

Mac Farlane 1994 Mac Farlane, R. E. and Muir, D. W., The NJOY Nuclear Data Processing System, Version 91, LA-12740-M, 1994

Makarious et al 1996 A.S. Makarious, I.I. Bashter, A. El-Asyed Abdo, W.A. Kansouh Measurement of fast neutrons and secondary gamma rays in graphite, Annals of Nuclear Energy, Vol. 23, 1996, pp. 617-623

Olah et al 1999 L. Oláh, A. Fenyvesi, J. Jordanova, A.M. El-Megrab, A.D. Majdeddin, Darsono, N. Perez, M.Y.A. Yousif, J. Csikai, Measurements and calculations of neutron 
leakage spectra from slabs irradiated with $9 \mathrm{Be}(\mathrm{d}, \mathrm{n}) 10 \mathrm{~B} 2 \mathrm{H}(\mathrm{d}, \mathrm{n}) 3 \mathrm{He}$ and $\mathrm{Pu}-\mathrm{Be}$ neutrons, Applied Radiation and Isotopes, Vol. 50, 1999, pp 479-486

Pellowitz 2013 D.B. Pelowitz (Ed.), MCNP6 ${ }^{\mathrm{TM}}$ User's Manual, Los Alamos National Laboratory Report, LA-CP-13-00634 (2013)

ROSFOND-2010 S. Zabrodskaya, A. Ignatyuk, V. Kosheev, M. Nikolaev, V. Pronyaev, ROSFOND - Russian national library of neutron data VANT (Voprosi Atomnoy Nauki i Techniki) Ser. Nucl. Const., 1-2 (2007), pp. 3-21

Veskrna et al 2014 Digitalized two parametric system for gamma/neutron spectrometry, Martin Veškrna, Zdeněk Matěj, Filip Mravec, Václav Přenosil, František Cvachovec, Michal Košt’ál, 18th Topical Meeting of the Radiation Protection \& Shielding Division of ANS, Knoxville, TN USA, 2014, 